\title{
Effects of Seed Soaking with La(NO3)3 on Anti-oxidization System of Soybean Roots
}

\author{
Tianhong Zhao ${ }^{1, a, \star}$, Tong Zhou ${ }^{2, b}$, Wei Wang ${ }^{3, c}$ Wanyu $\mathrm{Li}^{4, \mathrm{~d}}$ \\ ${ }^{1}$ College of Agronomy, Shenyang Agricultural University, Shenyang, Liaoning, China \\ ${ }^{2}$ College of Agronomy, Shenyang Agricultural University, Shenyang, Liaoning, China \\ ${ }^{3}$ College of Agronomy, Shenyang Agricultural University, Shenyang, Liaoning, China \\ ${ }^{4}$ College of Agronomy, Shenyang Agricultural University, Shenyang, Liaoning, China \\ a,*zth1999@163.com, Author for correspondence, ${ }^{b} 1960057783 @ q q . c o m,{ }^{c}$ syau1999@sina.com, \\ ${ }^{\mathrm{d}}$ zth@syau.edu.com
}

Keywords: Lanthaum Nitrate; Yield; Antioxidant Ability; Seed Soaking; Soybean

\begin{abstract}
Rare earth (RE) is extensively applied in China, especially in agriculture. This experiment investigated the effects of seed soaking with lanthanum nitrate [La-0(CK), $\mathrm{La}-50(50 \mathrm{mg} \cdot \mathrm{L}-1)$, La-100(100 $\mathrm{mg} \cdot \mathrm{L}-1)$ and $\mathrm{La}-150(150 \mathrm{mg} \cdot \mathrm{L}-1)]$ on reactive oxygen species, anti-oxidative substrates, anti-oxidative enzymes in soybean roots and its yield. The results showed that compared with other treatments, La concentration at $100 \mathrm{mg} \cdot \mathrm{L}-1$ decreased the superoxide anion production rate, and hydrogen peroxide content, and increased the activities of superoxide dismutase(SOD), peroxidase (POD), and the contents of Ascorbic acid (AsA), Glutathione(GSH) in soybean roots during the whole growth stage. Besides, the yield of soybean had the same trend. The results revealed that metabolism rates of reactive oxygen species are restrained with the antioxidant ability of anti-oxidative system strengthened with the increase of La concentration, which presents protective effect on soybean plant. However, when the La concentration is higher than some concentration with around $150 \mathrm{mg} \cdot \mathrm{L}-1$, the activities of anti-oxidative enzymes and anti-oxidative substrates reduce resulting in reactive oxygen species accumulating, so the yield declines, which represents injured effects on soybean.
\end{abstract}

\section{Introduction}

Since 1970s, rare earth (RE) micro-fertilizers have been used in agriculture production in China, which are salts of mixed Res, including $\mathrm{La}, \mathrm{Ce}, \mathrm{Pr}$ and $\mathrm{Nd}[1]$. With the application of rare earth (RE) in the crops, it can protect plants from the damages caused by UV-B, acid rain, heavy metal. Yan et al (1999) found that under low acidity of acid rain, REs could reduce the sensitivity of anti-oxidation enzymes of wheat to acid rain stress significantly and promote the resistance of anti-oxidation enzymes of wheat to acid rain [2]. However, Wen et al (2011) detected that the combined of La3+ and acid rain obviously destroyed the chloroplast ultrastructure of cell and aggravated the harmful effect of the single La3+ and acid rain on soybean seedlings [3]. Wang et al (2008) found that the distribution behaviors of heavy metals in horseradish could be affected by the type and concentration of Res [4]. Several relevant studies observed that using a rare earth fertilizer appropriately could increase crop yield and improved the quality of crops [5, 6].

China is an agricultural country and soybean is a main crop. Therefore, this study will observe the physiological biochemical characters of soybean roots at different growth stages with seed soaking by lanthanum nitrate, which demonstrates the positive effect on the soybean growth.

\section{Materials and Methods}

Plant Material and Growth Conditions. This study was finished at Farmland Experimental Station of Shenyang Agricultural University. This region belongs to a dry-cold winter and a warm-wet summer with a mean $650-700 \mathrm{~mm}$ of annual precipitation and $7.0-8.0^{\circ} \mathrm{C}$ temperature. The native soil is meadow brown soil, which is a main soil type for agricultural production in northern China. The test crop is soybean(Glycine max) . 
The experimental area had three micro plots, which were $3 \mathrm{~m} \times 3 \mathrm{~m}$ with a buffer zone of $1.0 \mathrm{~m}$ between each plot. Each plot was divided into four equal size blocks, which were cultivated different treatments of soybean seeds. The four treatments were (1) CK, which soybean seeds were soaked into the distilled water, (2) La-50, which soybean seeds were soaked into the content of 50mg.L-1 lanthanum nitrate solution, (3) La-100, which soybean seeds were soaked into the content of $100 \mathrm{mg} \cdot \mathrm{L}-1$ lanthanum nitrate solution, (4) La-150, which soybean seeds were soaked into the content of $150 \mathrm{mg} \cdot \mathrm{L}-1$ lanthanum nitrate solution. Each soybean seeds of different treatments were soaked into the solution for 24 hours and dried under the shady place. Soybean root samples were collected during the branching stage, flowering stage, podding stage and grain filling stage.

\section{Determination of Parameters}

The rate and content of ROS production included the rate of superoxide anion $\left(\mathrm{O}_{2}{ }^{i}\right)$ production measured by the hydroxylamine method and the content of hydrogen peroxide $\left(\mathrm{H}_{2} \mathrm{O}_{2}\right)$ which was determined by a spectrophotometer method [7]. The activity of superoxide dismutase (SOD) was measured by NBT photogenic reaction. The activity of peroxidase (POD) was measured by the guaiac-based phenol method[8]. The seed yield was weighted under natural air drying. Anti-oxidative matters included ascorbic acid (AsA) which was measured by a spectrophotometer method [9] and Glutathione (GSH) was extracted trichloroacetic acid (TDA), and then determined by photometer[10].

\section{Statistical Analysis}

Statistical analyses were carried out with the SPSS window version 16.0 (SPSS Inc., Chicago, USA) packages. One-way ANOVA was used for analysis of the changes, unless otherwise stated, the level of significance referred to in the results is $\mathrm{p}<0.05$.

\section{Results}

In the whole growing stage of soybean, the superoxide anion production rate and hydrogen peroxide content under different treatments had the same downtrend, which was CK>La-50>La-150>La-100. The superoxide anion production rate of soybean under high concentration of lanthanum nitrate was decreasing but when the concentration was over $100 \mathrm{mg} \cdot \mathrm{L}^{-1}$, the production rate was up. The variation trend was similar as hydrogen peroxide content. Compared to $\mathrm{CK}$, at the grain filling stage, the superoxide anion production rate had a significant difference between the treatments $(\mathrm{p}<0.05)$. But there was no significant difference detected at the other growing stage. Compared to CK, significant difference was detected during the growth stage except the flowering stage.
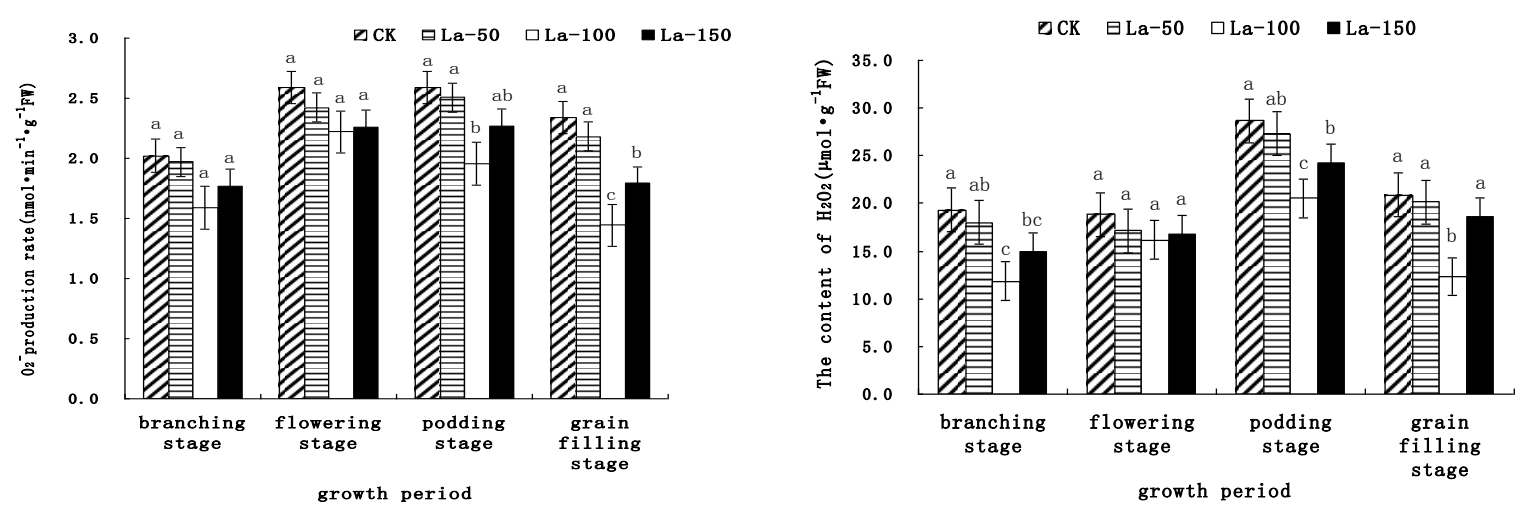

Figure. $1 \mathrm{O}_{2}{ }^{i}$ Production Rate and the Content of $\mathrm{H}_{2} \mathrm{O}_{2}$ under Different Treatments

With the extension of the soybean growth period, all of them had the same downtrend, which was La-100> La-150> La-50 > CK. Compared to the variation trend of ROS production rate, the 
variation trend of the anti-oxidative enzymes activities was apparently contradictory. In the whole soybean growth period, with the concentration of lanthanum nitrate increasing, the anti-oxidative enzymes activities were more and more active, and when the concentration of lanthanum nitrate reached $100 \mathrm{mg} \cdot \mathrm{L}^{-1}$, the anti-oxidative enzyme activities were the more energetic than the others, however, the high concentration above $100 \mathrm{mg} \cdot \mathrm{L}^{-1}$ had a negative effect on the anti-oxidative enzymes activities. During the entire soybean growth period, compared to CK, the activities of superoxide dismutase were detected no significant difference between the treatments but the activities of peroxidase were detected significant difference at the podding stage $(\mathrm{p}<0.05)$.
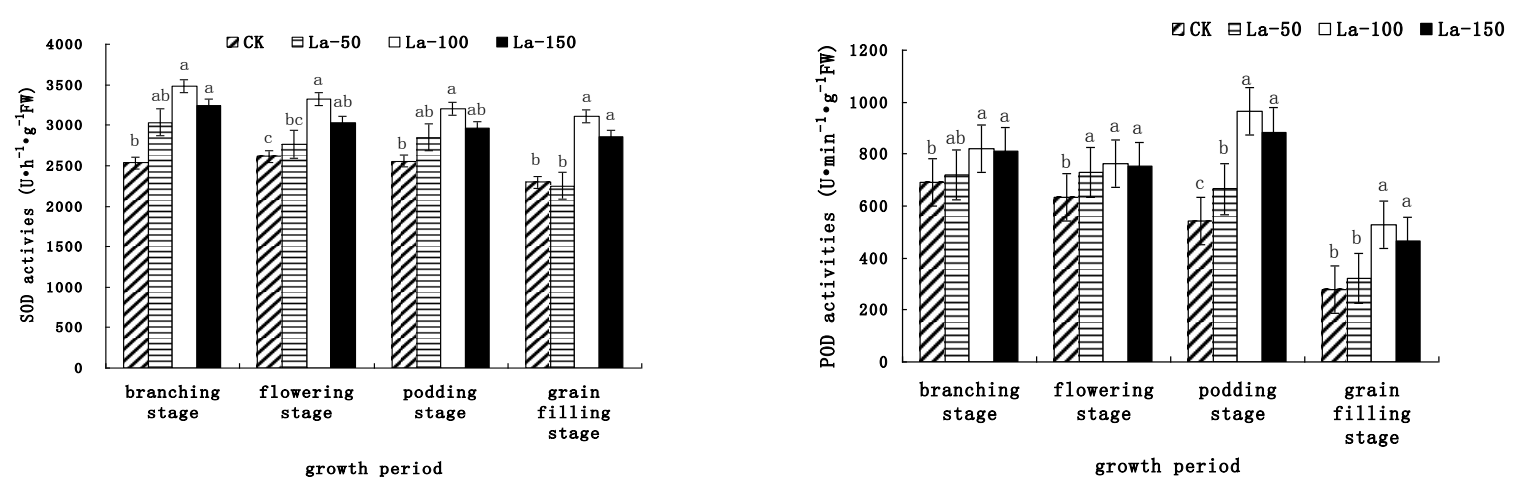

Figure. 2 SOD and POD Activities under Different Treatments

In this study the detected anti-oxidative matters were ascorbic acid (AsA) and Glutathione (GSH). During the soybean growth period, both of the two anti-oxidative matters owned the equivalent variation trend, which was La-100> La-150> La-50 > CK. In the flowering stage, compared to $\mathrm{CK}$, the content of AsA under different treatments was detected a significant difference, but there were no significant differences in the other growing stage $(p<0.05)$. Both at the flowering stage and the podding stage, compared to $\mathrm{CK}$, the content of GSH was discovered a significant difference $(\mathrm{p}<0.05)$ under different treatments.
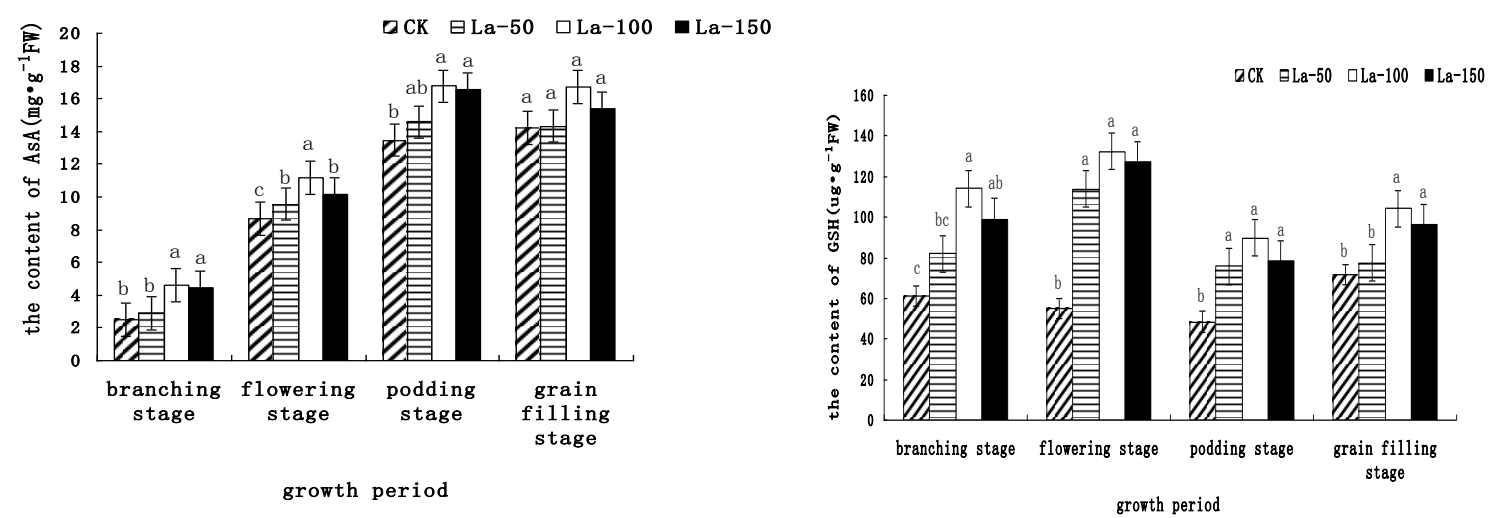

Figure 3 Content of AsA and GSH under Different Treatments

Compared to CK, the seed number of per plant, the weight of per plant, 100-seed weight and grains of per pod under different treatments were higher. Among the four treatments, every indexes of La-100 were the highest which did a positive effect on the soybean growth $(\mathrm{p}<0.05)$.

Table 1 The Variation of Soybean Yield under Different Treatments

\begin{tabular}{lcccccccc}
\hline & $\begin{array}{c}\text { the seed } \\
\text { number } \\
\text { of per } \\
\text { plant }\end{array}$ & $\begin{array}{c}\text { Relative } \\
\text { Change } \\
\text { Rate } \\
(\%)\end{array}$ & $\begin{array}{c}\text { the } \\
\text { weight } \\
\text { of per } \\
\text { plant }(\mathrm{g})\end{array}$ & $\begin{array}{c}\text { Relative } \\
\text { Change } \\
\text { Rate } \\
(\%)\end{array}$ & $\begin{array}{c}100-\text { seed } \\
\text { weight(g) }\end{array}$ & $\begin{array}{c}\text { Relative } \\
\text { Change } \\
\text { Rate } \\
(\%)\end{array}$ & $\begin{array}{c}\text { grains } \\
\text { of per } \\
\text { pod }\end{array}$ & $\begin{array}{c}\text { Relative } \\
\text { Change } \\
\text { Rate } \\
(\%)\end{array}$ \\
\hline CK & 154.80 & & 38.08 & & 23.37 & & 76.09 & \\
La-50 & 160.94 & 3.96 & 38.72 & 1.68 & 24.11 & 3.17 & 81.29 & 6.83 \\
La-100 & 177.03 & 14.36 & 43.28 & 13.66 & 24.24 & 3.72 & 85.14 & 11.89 \\
La-150 & 164.80 & 6.46 & 40.20 & 5.57 & 24.14 & 3.29 & 79.23 & 4.12 \\
\hline
\end{tabular}




\section{Conclusions}

As showed in the paper, both of superoxide anion production rate and the content of hydrogen peroxide had the same variation trend, which was CK>La-50>La-150>La-100. Under high concentration of lanthanum nitrate, superoxide anion production rate and the content of hydrogen peroxide became lower than the former which indicated that high concentration of lanthanum nitrate could relieve the senescence of soybean roots.

The soybean roots anti-oxidative enzymes and matters involved in this study concluded SOD, POD, AsA, GSH. The variation trends of them were all La-100> La-150>La-50>CK. With the concentration of lanthanum nitrate increasing, anti-oxidative enzymes activities became more and more active and the content of anti-oxidative matters accumulates more and more. However, when the concentration of lanthanum nitrate passed $100 \mathrm{mg} \cdot \mathrm{L}^{-1}$, there was a downtrend. The results indicated that high concentration of lanthanum nitrate which was under some concentration could relieve the senescence of soybean roots, however, when it passed the range, the positive effects would disappear even did a negative effect on soybean roots.

In this study, it could be drawn to the similar conclusion that the appropriate concentration of lanthanum nitrate (about $100 \mathrm{mg} \cdot \mathrm{L}^{-1}$ ) could do a positive effect on the soybean roots and it could improve the soybean yield.

\section{Acknowledgements}

This work was financially supported by the National Natural Science Foundation of China (NO. 30970448) , Program for Excellent Talents in University of Liaoning (LJQ2011072) and Project for Scientific and Technological Innovation of National Undergraduate (2014).

\section{Reference}

[1] Z.Y.Hu, H.Richter, G.Sparovek. Physiological and biochemical effects of rare earth elements on plants and their agricultural significance: a review, J. Plant. Nutr. 27 (2004):183 -220.

[2] C.L.Yan, Y.T.Hong, X.K.Yang. Biological effect of rare-earth elements on anti-oxidation enzymes in wheat under acid rain stress, Chinese Science Bulletin, 2 (1999):146-149.

[3] K.J.Wen, C.J. Liang, L.H. Wang. Combined effects of lanthanumion and acid rain on growth, photosynthesis and chloroplast ultrastructure in soybean seedlings, Chemosphere, 84 (2011):601-608.

[4] L.H.Wang, X.H.Huang, Q.Zhou. Effects of rare earth elements on the distribution of mineral elements and heavy metals in horseradish, Chemosphere, 73 (2008): 314-319.

[5] S.R.Yan, X.H.Huang, Q.Zhou. Effect of lanthanum (III) on reactive oxygen metabolism of soybean seedlings under supplemental UV-B radiation, Journal of rare earths, 25(2007):352 -358.

[6] J.C.Wang, X.S.Liu, J. Yang. Development and Prospect of Rare Earth Functional Biomaterials for Agriculture in China, Journal of rare earths, 24(2006): 427-431.

[7] Z.C.Tang, J.M.Wei. Experimental guide of Modern Plant Physiology, Science Press, Beijing, 1999, pp.305-306.

[8] Q.Zou. Plant Physiology Experiment Guide, China Agriculture Press, Beijing, 2000, pp.163-168. 
[9] J.X.Chen, X.F. Wang. Plant Physiology Experiment Guide, second Ed., South China University of Technology Press, Guangzhou, 2006, pp.72-73.

[10]M.E. Anderson. Determination of glutathione and glutathione disulphide in biological samples, Methods Enzymolecular, 113(1985): 548-555. 